\title{
Kinetic and Thermodynamic Studies on the Phosphate Adsorption Removal by Dolomite Mineral
}

\author{
Xiaoli Yuan, Wentang Xia, Juan An, Jianguo Yin, Xuejiao Zhou, and Wenqiang Yang \\ School of Metallurgy and Material Engineering, Chongqing University of Science and Technology, Chongqing 401331, China \\ Correspondence should be addressed to Wentang Xia; wentangx@163.com
}

Received 26 November 2014; Revised 15 January 2015; Accepted 26 January 2015

Academic Editor: Apostolos Giannis

Copyright ( 2015 Xiaoli Yuan et al. This is an open access article distributed under the Creative Commons Attribution License, which permits unrestricted use, distribution, and reproduction in any medium, provided the original work is properly cited.

\begin{abstract}
The efficiency of dolomite to remove phosphate from aqueous solutions was investigated. The experimental results showed that the removal of phosphate by dolomite was rapid (the removal rate over $95 \%$ in $60 \mathrm{~min}$ ) when the initial phosphate concentration is at the range of 10-50 mg/L. Several kinetic models including intraparticle diffusion model, pseudo-first-order model, Elovich model, and pseudo-second-order model were employed to evaluate the kinetics data of phosphate adsorption onto dolomite and pseudosecond-order model was recommended to describe the adsorption kinetics characteristics. Further analysis of the adsorption kinetics indicated that the phosphate removal process was mainly controlled by chemical bonding or chemisorption. Moreover, both Freundlich and Langmuir adsorption isotherms were used to evaluate the experimental data. The results indicated that Langmuir isotherm was more suitable to describe the adsorption characteristics of dolomite. Maximum adsorption capacity of phosphate by dolomite was found to be $4.76 \mathrm{mg}$ phosphorous/g dolomite. Thermodynamic studies showed that phosphate adsorption was exothermic. The study implies that dolomite is an excellent low cost material for phosphate removal in wastewater treatment process.
\end{abstract}

\section{Introduction}

Phosphorus is an indispensable element for animals and plants on the earth. However, excessive phosphorus in water bodies can cause eutrophication. When the concentration of phosphorus in water bodies is higher than $0.02 \mathrm{mg} / \mathrm{L}$, the eutrophication would happen [1]. So it is necessary to eliminate phosphate ions from water.

Several techniques have been applied to the removal of phosphate from wastewater, and the frequently used methods include chemical precipitation [2], biological treatments [3], and adsorption [4]. Among these, adsorption is considered to be a reliable and effective technique for phosphate removal. To choose the adsorption method, both high adsorption capacity and low cost are key issues to be considered. A great attention has been paid to low-cost adsorbents over past years, especially to the natural mineral and industrial waste, such as limestone [5], iron based compounds [6], aluminum based compounds [7], natural zeolite [8], iron oxide tailing [9], ferric sludge [10], blast furnace slag [11], and other materials.
It is well recognized that dolomite is an effective and low-cost adsorbent for phosphate. However, related studies of adsorption mechanism of dolomite, such as the kinetic and thermodynamic adsorption of phosphate by dolomite minerals, had not been reported yet. It is of great importance to study the adsorption mechanism of phosphate by dolomite to clarify the absorption phenomena and reaction processes and to determine the optimal adsorption conditions in practical production. Dolomite contains $\mathrm{Ca}^{2+}$, which can be dissolved in the solution and can then react with phosphate anions to form phosphate precipitates, such as $\mathrm{Ca}_{10}\left(\mathrm{PO}_{4}\right)_{6}(\mathrm{OH})_{2}$ [12]. In a previous paper [13], the effects of initial phosphate concentration, reaction time, reaction temperature, and adsorbent dosage on the phosphate removal rates were investigated. The experiments of phosphate adsorption removal results show that the phosphate removal rates exceed 99\%; the equilibrium phosphate concentrations after phosphate removal reaction completely accord with the requirement of national discharge standards of the second category pollution GB $1 \mathrm{~A}(\mathrm{TP}=0.5 \mathrm{mg} / \mathrm{L})$ in China. 
The objective of the present study was focused on the phosphate adsorption kinetics and thermodynamics of dolomite. Several kinetic models including intraparticle diffusion model, pseudo-first-order model, Elovich model, and pseudo-second-order model were used to fit the kinetic experimental data and the corresponding kinetic parameters were calculated. The isotherm models of Langmuir and Freundlich equations were applied to evaluate the adsorption equilibrium.

\section{Materials and Methods}

2.1. Materials. Dolomite used in this research (mass percent $\mathrm{CaO} 29.68 \%, \mathrm{SiO}_{2} 5.13 \%$, and $\mathrm{MgO} 16.55 \%$ ) was obtained from Daye, Hubei, China; dolomite was crushed and sieved to smaller than $0.15 \mathrm{~mm}$ in particle size before it was used. An appropriate volume of $0.1 \mathrm{~mol} / \mathrm{L} \mathrm{HCl}$ (AR, Chemical Reagent Factory, Chongqing Chuandong Chemical (Group) Co., Ltd) or $0.1 \mathrm{~mol} / \mathrm{L} \mathrm{NaOH}$ (AR, Shanghai Fengxian Fengcheng Reagent Factory) was used to adjust the $\mathrm{pH}$ of the solution.

2.2. Experimental Methods. Adsorption experiments were carried out as the following procedure. Firstly, a defined volume of phosphate stock solution was diluted to the experimental concentration by adding deionized water in $100 \mathrm{~mL}$ glass round-bottom flasks immersed in a thermostatic shaker bath. The $\mathrm{pH}$ of the solution was then adjusted to the desired value and a defined amount of adsorbent was added. The mixture was stirred at $250 \mathrm{rpm}$ for a defined period, using a potentiometer to regulate the stirring speed. Then the liquid samples were collected and filtering process was applied to separate solid from liquid, and the filtrate was taken for $\mathrm{P}$ analysis.

To investigate the influence of $\mathrm{pH}$ on the phosphate adsorption by dolomite, experiments were carried out on the conditions of reaction temperature $20^{\circ} \mathrm{C}$, stirring speed $250 \mathrm{rpm}$, dolomite dosage $10 \mathrm{~g} / \mathrm{L}$, initial phosphate concentration $50 \mathrm{mg} / \mathrm{L}$, and reaction time $60 \mathrm{~min}$. Phosphate adsorption kinetics studies were evaluated in the conditions with different adsorption time, different initial phosphate concentrations, and fixed dolomite dosage $(10 \mathrm{~g} / \mathrm{L})$ and $\mathrm{pH}$ 9.5 at $20^{\circ} \mathrm{C}$. Five levels of initial phosphate concentrations $(10,30,50,70$, and $100 \mathrm{mg} \mathrm{P} / \mathrm{L})$ and adsorption time (20, $40,60,80$, and $100 \mathrm{~min}$ ) were used. The effect of adsorption temperature on phosphate removal was performed at four different temperatures $\left(20,40,60\right.$, and $\left.80^{\circ} \mathrm{C}\right)$ for $60 \mathrm{~min}$ with fixed dolomite dosage $(10 \mathrm{~g} / \mathrm{L})$ and $\mathrm{pH}(9.5)$, and the initial phosphate concentration varies from 10 to $90 \mathrm{mg} \mathrm{P} / \mathrm{L}$.

The $\mathrm{pH}$ of solutions was measured by $\mathrm{pH}$ meter (Model Delta 320, METTLER-TOLED Instruments (Shanghai) Co., China). The phosphate concentration of all samples including wastewater was analyzed by bismuth phosphor molybdenum blue spectrophotometric method (Model TU1810, Beijing Puxi Science and Technology Instrument Co. Ltd., China). Phase analyses of dolomite before and after phosphate adsorption were conducted by X-ray diffraction (XRD) (Model D/max 2500 PC, Rigaku, Japan) with Cu Ka radiation.
2.3. Data Evaluation. In order to investigate the potential rate-controlling step of the phosphate adsorption process, several kinetics models, including intraparticle diffusion model, pseudo-first-order model, Elovich model, and pseudo-second-order model were employed to evaluate phosphate adsorption kinetics performance. The following equations were applied for describing the four kinetics models, respectively, [14-17]:

intraparticle diffusion model:

$$
Q_{t}=c+k_{m} t^{1 / 2}
$$

pseudo-first-order model:

$$
\frac{1}{Q_{t}}=\frac{k_{1}}{Q_{e} t}+\frac{1}{Q_{e}},
$$

Elovich model:

$$
Q_{t}=\frac{1}{\beta \ln (\alpha \beta)}+\frac{1}{\beta} \ln t,
$$

pseudo-second-order model:

$$
\frac{t}{Q_{t}}=\frac{1}{k_{2} Q_{e}^{2}}+\frac{t}{Q_{e}},
$$

where $t(\mathrm{~h})$ is the contact time of adsorption experiment, $Q_{e}(\mathrm{mg} / \mathrm{g})$ and $Q_{t}(\mathrm{mg} / \mathrm{g})$ are, respectively, the adsorption capacity at equilibrium and at any time $t, \alpha(\mathrm{mg} /(\mathrm{g} \cdot \mathrm{min}))$ is the initial adsorption rate constant and the parameter $\beta(\mathrm{g} / \mathrm{mg})$ is related to the extent of surface coverage and activation energy for chemisorption, $k_{1}(1 / \mathrm{min})$ is the rate constant of the pseudo-first-order model, $k_{m}\left(\mathrm{mg} /\left(\mathrm{g} \cdot \mathrm{min}^{1 / 2}\right)\right)$ is the rate constant of the intraparticle diffusion model and $c$ is obtained from the intercept, and $k_{2}(\mathrm{~g} /(\mathrm{mg} \cdot \mathrm{min}))$ is the rate constant of the pseudosecond-order model. The initial adsorption rate is $k_{2} Q_{e}^{2}(\mathrm{mg} /(\mathrm{g} \cdot \mathrm{min}))$.

Adsorption isotherms data were evaluated using the Langmuir and Freundlich equations, respectively, expressed in the following equations $[18,19]$ :

$$
\begin{gathered}
Q_{e}=\frac{C_{e} b Q_{\max }}{\left(1+b C_{e}\right)}, \\
Q_{e}=k C_{e}^{1 / n} .
\end{gathered}
$$

The linear equations of these two experiential models are as follows:

$$
\begin{gathered}
\frac{C_{e}}{Q_{e}}=\frac{1}{\left(b Q_{\max }\right)}+\frac{C_{e}}{Q_{\max }}, \\
\log Q_{e}=\log k+\frac{\left(\log C_{e}\right)}{n},
\end{gathered}
$$


TABLE 1: Influence of $\mathrm{pH}$ value on phosphate removal by dolomite.

\begin{tabular}{lcc}
\hline Initial $\mathrm{pH}$ & $\begin{array}{c}\text { Residual phosphate } \\
\text { concentration/(mg/L) }\end{array}$ & $\begin{array}{c}\text { Phosphate removal } \\
\text { rate/\% }\end{array}$ \\
\hline 3.52 & 3.75 & 92.50 \\
5.56 & 3.65 & 92.70 \\
7.39 & 2.98 & 94.04 \\
9.50 & 1.46 & 97.08 \\
10.39 & 1.53 & 96.40 \\
11.35 & 1.69 & 96.20 \\
12.37 & 3.02 & 93.96 \\
\hline
\end{tabular}

where $C_{e}$ is the equilibrium concentration of phosphate in the solution $(\mathrm{mg} / \mathrm{L}), Q_{e}$ is the phosphate concentrations in the solid adsorbent $(\mathrm{mg} / \mathrm{g}), Q_{\max }$ is the maximum adsorption capacity $(\mathrm{mg} / \mathrm{g}), k$ is a constant related to the adsorption capacity $\left(\mathrm{mg}^{1-1 / n} \mathrm{~L}^{1 / n} \mathrm{~g}\right), b$ is a constant related to the energy of adsorption $(\mathrm{L} / \mathrm{g})$, and $n$ is a constant related to the energy of adsorption.

\section{Results and Discussion}

3.1. Influence of $\mathrm{pH}$. The result of the influence of $\mathrm{pH}$ on the phosphate adsorption by dolomite was listed in Table 1 . As can be seen from Table 1, the phosphate removal rate increases rapidly with $\mathrm{pH}$ value increasing when the $\mathrm{pH}$ value is lower than 9.5. This may be explained by the fact that the phosphate removal is related both to the dissolution of $\mathrm{Ca}^{2+}$ ions from adsorbent and to the polyprotic nature of phosphate [20]. For $\mathrm{KH}_{2} \mathrm{PO}_{4}$ solution, the main orthophosphate compound is changed with the $\mathrm{pH}$ value (i.e., conversion of $\mathrm{H}_{3} \mathrm{PO}_{4} \Rightarrow \mathrm{H}_{2} \mathrm{PO}_{4}^{-} \Rightarrow \mathrm{HPO}_{4}{ }^{2-} \Rightarrow \mathrm{PO}_{4}{ }^{3-}$ with increasing $\mathrm{pH}$ ). When $\mathrm{pH}$ value is about 9.5, $\mathrm{HPO}_{4}{ }^{2-}$ is the dominant compound in the solution. It is known that calcium phosphate precipitation is the predominant mechanism in phosphorus immobilization at higher $\mathrm{pH}$ value [21]. Therefore, dolomite dissolves to emerge partial $\mathrm{Ca}^{2+}$, and $\mathrm{Ca}^{2+}$ reacts with $\mathrm{HPO}_{4}{ }^{2-}$ and $\mathrm{PO}_{4}{ }^{3-}$ to form calcium phosphate. The dolomite samples before and after reactions have been checked by XRD and the result was shown in Figure 1. The main components of the sample after reaction include dolomite, quartz, and hydroxyl apatite; the maximum diffraction peak intensities of dolomite, quartz, and hydroxyl apatite are 16393, 622, and 279, respectively. It is obvious from Figure 1 that phosphate precipitated with calcium as hydroxyl apatite. However, the phosphate removal rate decreases with $\mathrm{pH}$ value increasing when the initial $\mathrm{pH}$ value is above 9.5. Obviously, the dissolved $\mathrm{Ca}^{2+}$ concentration will decrease with the initial $\mathrm{pH}$ value increasing, which causes the inhibition of calcium phosphate precipitation and thus reduces phosphate adsorption. In addition, $\mathrm{OH}^{-}$concentration in solution increases with the initial $\mathrm{pH}$ value increasing [22]. The inhibition of phosphate adsorption could also be ascribed to the competition between hydroxyl ions $\left(\mathrm{OH}^{-}\right)$and the phosphate ions on the dolomite surface. In addition, it can be seen from Table 1 that the phosphate removal rate achieves

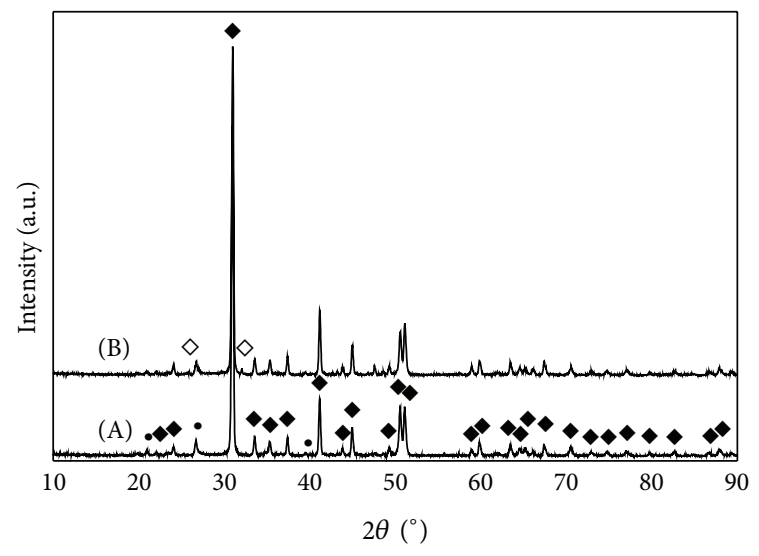

- $\mathrm{CaMg}\left(\mathrm{CO}_{3}\right)_{2}$

$\diamond \mathrm{Ca}_{10}\left(\mathrm{PO}_{4}\right)_{6}(\mathrm{OH})_{2}$

- $\mathrm{SiO}_{2}$

FIGURE 1: XRD patterns of the dolomite samples (A) before adsorption and (B) after adsorption (at $\mathrm{pH}$ value $=9.5$ ).

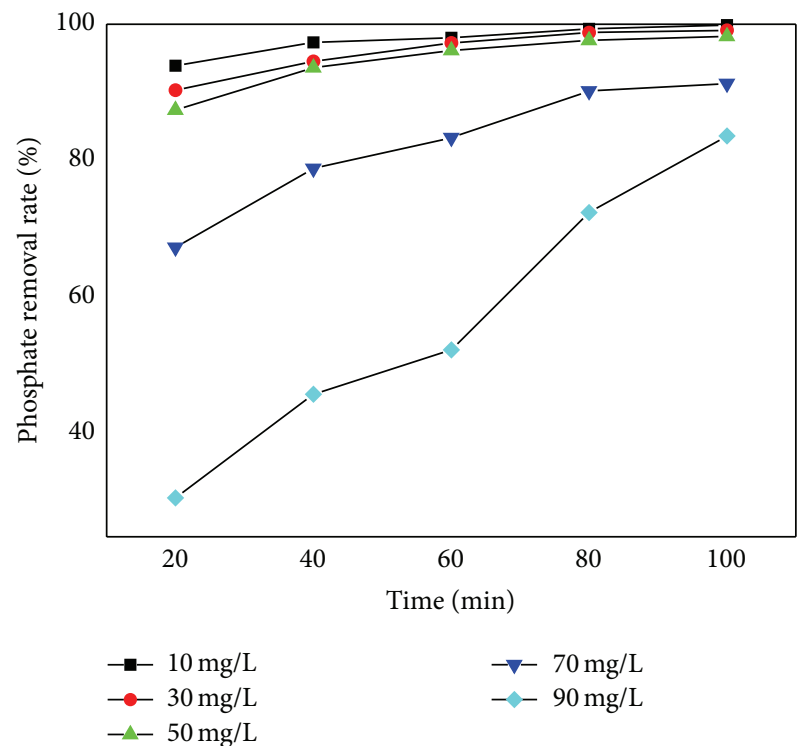

FIGURE 2: Kinetics of phosphate adsorption by dolomite.

92.50\% when the $\mathrm{pH}$ value is 3.52 . Considering the fact that the calcium phosphate precipitation can be neglected when the $\mathrm{pH}$ value is relatively low [21], it is clear that the considerable phosphate removal rate $(92.50 \%)$ at $\mathrm{pH}=3.52$ is fulfilled by the process of phosphate adsorption to dolomite. So, it can be concluded that adsorption to dolomite is the main phosphate removal process in present work. Although dolomite contains $\mathrm{Mg}$ element, previous works reported that the phosphate removal by fixation with $\mathrm{Mg}^{2+}$ ions was not accomplished or it was low [23]. So the main effective component for phosphate adsorption on dolomite is $\mathrm{Ca}^{2+}$.

3.2. Adsorption Kinetics. Figure 2 showed the kinetics results of phosphate removal by dolomite. Results indicated that 


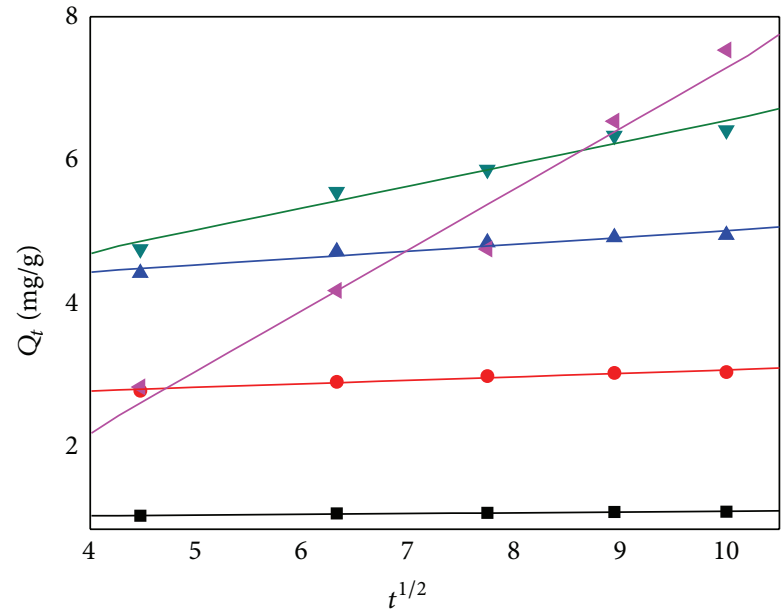

(a)

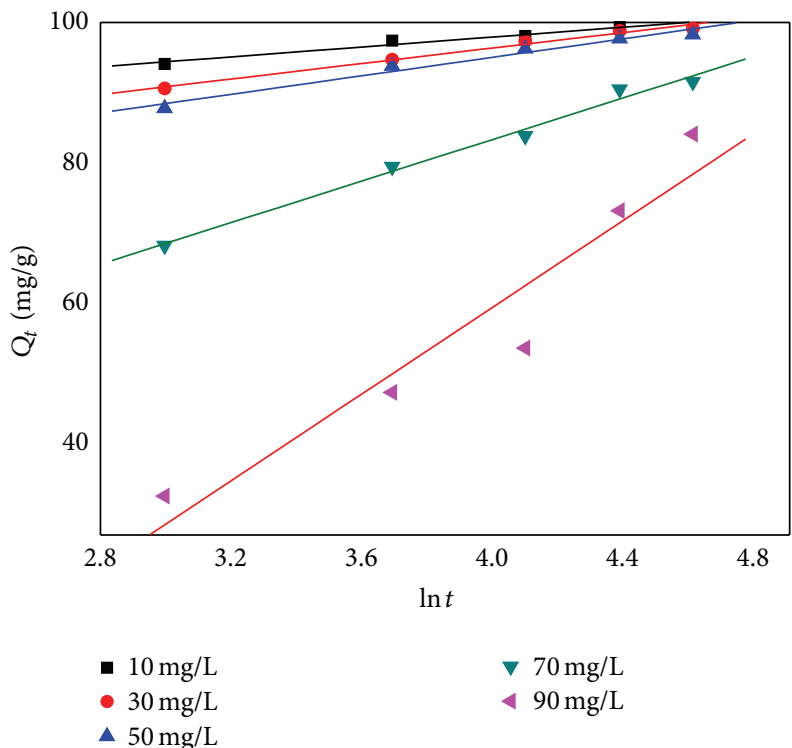

(c)

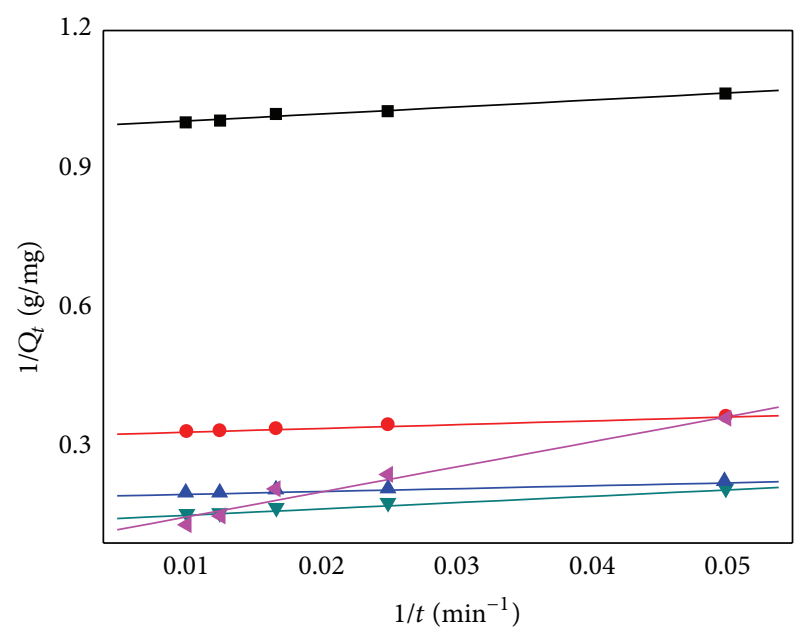

(b)

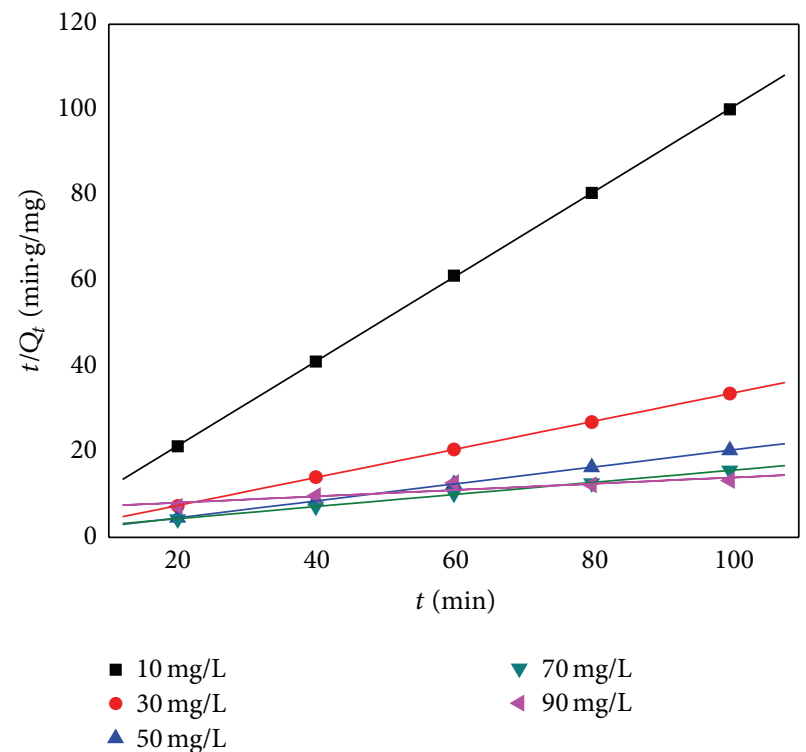

(d)

FiguRE 3: The kinetic plots for sorption of phosphate using different models: (a) intraparticle diffusion model; (b) pseudo-first-order model; (c) the Elovich model; and (d) pseudo-second-order model.

the rate of phosphate removal by dolomite was quite rapid. The phosphate removal rate increased rapidly before $80 \mathrm{~min}$. With the adsorption time further increasing, the phosphate removal rate increased slowly.

The experimental data were employed to derive the kinetic parameters using the four different models. The fitting of the experimental data to the linear forms of the four adsorption kinetics models was shown in Figures 3(a)$3(d)$, respectively. The parameters obtained using these four models are listed in Table 2. It is seen that the pseudo-secondorder model shows a good agreement with the experimental data; the correlation coefficients $\left(R^{2}\right)$ of pseudo-second-order model in all different initial phosphate concentrations are all above 0.99 , which are higher than those of Elovich model, intraparticle diffusion model, and pseudo-first-order model. In adsorption processes, a pseudo-second-order mode is generally interpreted to mean that the mechanism of the process is mainly controlled by chemical bonding or chemisorption. This would imply that the cause of phosphate adsorption onto the dolomite involves valency forces through sharing or exchanging electrons between sorbate and sorbent [24].

3.3. Adsorption Isothermal Models. Figure 4 showed the effect of adsorption temperature on phosphate removal. It can be seen from Figure 4 that the adsorption reaction nearly reached equilibrium at initial phosphate concentration at about $50 \mathrm{mg} / \mathrm{L}$ under the experimental conditions tested.

The plots of fitting the experimental data to the linear forms of Freundlich and Langmuir models were shown in Figure 5. The values of the Freundlich and Langmuir constants and the correlation coefficients for dolomite are presented in Table 3. Results showed that Langmuir equation gave a better fit than the Freundlich equation according to their correlation coefficients. In all cases, correlation 
TABLE 2: Estimated kinetic model parameters for phosphate adsorption by dolomite.

\begin{tabular}{|c|c|c|c|c|}
\hline \multicolumn{5}{|c|}{ Intraparticle diffusion model: $Q_{t}=c+k_{m} t^{1 / 2}$} \\
\hline Initial phosphate concentration/(mg/L) & $c$ & $k_{m} /\left(\mathrm{mg} /\left(\mathrm{g} \cdot \min ^{1 / 2}\right)\right)$ & $R^{2}$ & $\mathrm{SD}$ \\
\hline 10 & 0.8990 & 0.0104 & 0.9401 & 0.00661 \\
\hline 30 & 2.5134 & 0.0490 & 0.9518 & 0.02769 \\
\hline 50 & 4.0065 & 0.0966 & 0.9222 & 0.07055 \\
\hline 70 & 3.4407 & 0.3089 & 0.9682 & 0.14076 \\
\hline 90 & -1.3036 & 0.8581 & 0.9630 & 0.4227 \\
\hline \multicolumn{5}{|c|}{ Pseudo-first-order model: $1 / Q_{t}=k_{1} / Q_{e} t+1 / Q_{e}$} \\
\hline Initial phosphate concentration/(mg/L) & $k_{1} /\left(\min ^{-1}\right)$ & $Q_{e} /(\mathrm{mg} / \mathrm{g})$ & $R^{2}$ & SD \\
\hline 10 & 1.5421 & 1.0110 & 0.9821 & 0.0039 \\
\hline 30 & 2.5160 & 3.0426 & 0.9805 & 0.0022 \\
\hline 50 & 3.1923 & 5.0669 & 0.9989 & 0.0004 \\
\hline 70 & 9.5929 & 6.9324 & 0.9826 & 0.0035 \\
\hline 90 & 57.4628 & 10.4811 & 0.9631 & 0.0201 \\
\hline \multicolumn{5}{|c|}{ Elovich model: $Q_{t}=1 / \beta \ln (\alpha \beta)+(1 / \beta) \ln t$} \\
\hline Initial phosphate concentration/(mg/L) & $\alpha /(\mathrm{mg} /(\mathrm{g} \cdot \min ))$ & $\beta /(\mathrm{g} / \mathrm{mg})$ & $R^{2}$ & SD \\
\hline 10 & 3.7975 & 0.2751 & 0.9766 & 0.41284 \\
\hline 30 & 6.1505 & 0.1757 & 0.9866 & 0.48756 \\
\hline 50 & 7.5168 & 0.1471 & 0.9731 & 0.82918 \\
\hline 70 & 30.7053 & 0.0655 & 0.9886 & 1.20612 \\
\hline 90 & 20.0906 & 0.0314 & 0.9182 & 0.95821 \\
\hline \multicolumn{5}{|c|}{ Pseudo-second-order model: $t / Q_{t}=1 / k_{2} Q_{e}^{2}+t / Q_{e}$} \\
\hline Initial phosphate concentration/(mg/L) & $k_{2} /(\mathrm{g} /(\mathrm{mg} \cdot \mathrm{min}))$ & $Q_{e} /(\mathrm{mg} / \mathrm{g})$ & $R^{2}$ & SD \\
\hline 10 & 0.5637 & 1.0148 & 1.0000 & 0.2412 \\
\hline 30 & 0.1168 & 3.0586 & 0.9999 & 0.0901 \\
\hline 50 & 0.0602 & 5.0743 & 1.0000 & 0.0185 \\
\hline 70 & 0.0129 & 7.0877 & 0.9985 & 0.1978 \\
\hline 90 & 0.0008 & 13.6519 & 0.9903 & 1.1780 \\
\hline
\end{tabular}

TABLE 3: Characteristic parameters and determination coefficients of the experimental data according to Freundlich and Langmuir equations.

\begin{tabular}{lcccccrrr}
\hline & \multicolumn{4}{c}{ Langmuir equation } & \multicolumn{4}{c}{ Freundlich equation } \\
Temperature $\left({ }^{\circ} \mathrm{C}\right)$ & \multicolumn{3}{c}{$C_{e} / Q_{e}=1 /\left(b Q_{\max }\right)+C_{e} / Q_{\max }$} & \multicolumn{3}{c}{$\lg Q_{e}=\lg k+\left(\lg C_{e}\right) / n$} \\
& $b(\mathrm{~L} / \mathrm{g})$ & $Q_{\max }(\mathrm{mg} / \mathrm{g})$ & $R^{2}$ & $\mathrm{SD}$ & $k\left(\mathrm{mg}^{1-1 / n} \mathrm{~L}^{1 / n} \mathrm{~g}\right)$ & $1 / n$ & $R^{2}$ \\
\hline 20 & 11.56 & 4.76 & 0.9958 & 0.2871 & 2.48 & 0.276 & 0.6645 & 0.2096 \\
40 & 9.64 & 4.00 & 0.9857 & 0.7333 & 1.67 & 0.326 & 0.6334 & 0.2100 \\
60 & 5.83 & 3.71 & 0.9812 & 0.9462 & 1.45 & 0.336 & 0.6924 & 0.1856 \\
80 & 3.06 & 3.25 & 0.9694 & 1.4949 & 1.20 & 0.345 & 0.6270 & 0.1998 \\
\hline
\end{tabular}

coefficients corresponding to Freundlich equation were lower than those corresponding to Langmuir equation. The fact that dolomite has a relatively higher monolayer adsorption capacity supports the possibility of the adsorption mechanism. The value of the Langmuir constant $Q_{\max }$ was found to be $4.76 \mathrm{mg} / \mathrm{g}$. Comparisons with other adsorbents indicate that the adsorption capacity of dolomite is good. For example, it was reported that adsorption capacities of hematite [25] and furnace slag [26] were $3 \mathrm{mg} / \mathrm{g}$ and $0.65 \mathrm{mg} / \mathrm{g}$ P, respectively.

The essential characteristics of the Langmuir isotherm can be expressed by a dimensionless constant called equilibrium parameter $R_{0}$ [27]:

$$
R_{0}=\frac{1}{\left(1+b C_{0}\right)},
$$

where $b$ is the Langmuir constant, $C_{0}$ is the initial concentration $(\mathrm{mg} / \mathrm{g})$, and $R_{0}$ values indicate the type of isotherm. The value of $R_{0}$ indicates the type of the isotherm to be either for unfavorable adsorption, $R_{0}>1$, for linear adsorption, $R_{0}$ $=1$, for favorable adsorption, $0<R_{0}<1$, or for irreversible adsorption, $R_{0}=0$.

In the present work, the $R_{0}$ values on the initial phosphate concentrations of $10 \mathrm{mg} / \mathrm{L}, 30 \mathrm{mg} / \mathrm{L}, 50 \mathrm{mg} / \mathrm{L}$, and $90 \mathrm{mg} / \mathrm{L}$ are in Table 4 . The $R_{0}$ values were found to be between 0 and 1 for all the concentrations of phosphate studied; therefore, the phosphate adsorption by dolomite belonged to favorable adsorption.

3.4. Thermodynamic Parameters of Adsorption. From Figure 4, the phosphate removal rate decreased with the 


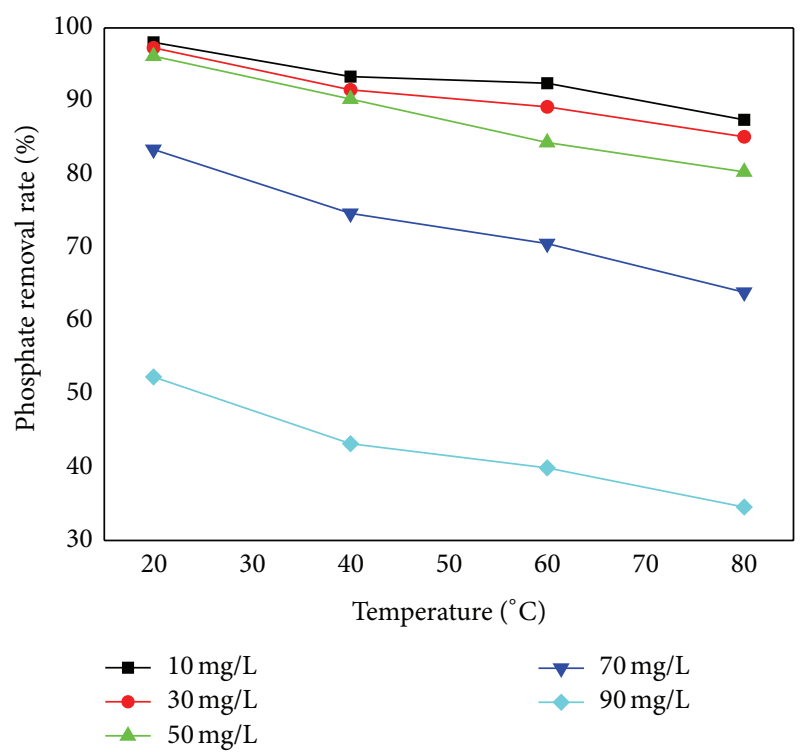

FIGURE 4: Effect of adsorption temperature on phosphate removal.

TABLE 4: Computation result of $R_{0}$.

\begin{tabular}{lccccc}
\hline$b(\mathrm{~L} / \mathrm{g})$ & \multirow{5}{*}{10} & 30 & $\begin{array}{c}C_{0}(\mathrm{mg} / \mathrm{L}) \\
50\end{array}$ & 70 & 90 \\
& & \multicolumn{5}{c}{$R_{0}$} \\
\hline 11.56 & 0.0086 & 0.0029 & 0.0017 & 0.0012 & 0.0010 \\
9.64 & 0.0011 & 0.0004 & 0.0002 & 0.0002 & 0.0001 \\
5.83 & 0.0169 & 0.0057 & 0.0034 & 0.0024 & 0.0019 \\
3.06 & 0.0316 & 0.0108 & 0.0065 & 0.0046 & 0.0036 \\
\hline
\end{tabular}

TABLE 5: Thermodynamic parameters for the adsorption of phosphate on dolomite.

\begin{tabular}{|c|c|c|c|}
\hline $\begin{array}{l}\text { Temperature } \\
(K)\end{array}$ & $\begin{array}{c}\Delta G^{\theta} \\
(\mathrm{KJ} / \mathrm{mol})\end{array}$ & $\begin{array}{c}\Delta H^{\theta} \\
(\mathrm{KJ} / \mathrm{mol})\end{array}$ & $\begin{array}{c}\Delta S^{\theta} \\
(\mathrm{J} / \mathrm{K} / \mathrm{mol})\end{array}$ \\
\hline 293 & -3.06 & \multirow{4}{*}{-5.85} & \multirow{4}{*}{-10.17} \\
\hline 313 & -2.71 & & \\
\hline 333 & -2.45 & & \\
\hline 353 & -2.25 & & \\
\hline
\end{tabular}

increase of adsorption temperature, especially for the sample with relatively high initial phosphate concentration. Which indicates that phosphate adsorption on the dolomite is exothermic reaction.

The change of Gibbs free energy is obtained using the following relationship:

$$
\Delta G^{\theta}=-R T \ln k,
$$

where $R$ is the gas constant, $k$ is the equilibrium constant (obtained from Freundlich equation), and $T(K)$ is the temperature. The negative values of $\Delta G^{\theta}$ indicate the spontaneous nature of adsorption (Table 5). The standard Gibbs free energies $\left(\Delta G^{\theta}\right)$ of the adsorption by dolomite were -3.06 , $-2.71,-2.45$, and $-2.25 \mathrm{KJ} / \mathrm{mol}$ at $293,313,333$, and $353 \mathrm{~K}$, respectively. The increase in $\Delta G^{\theta}$ values for minerals with the

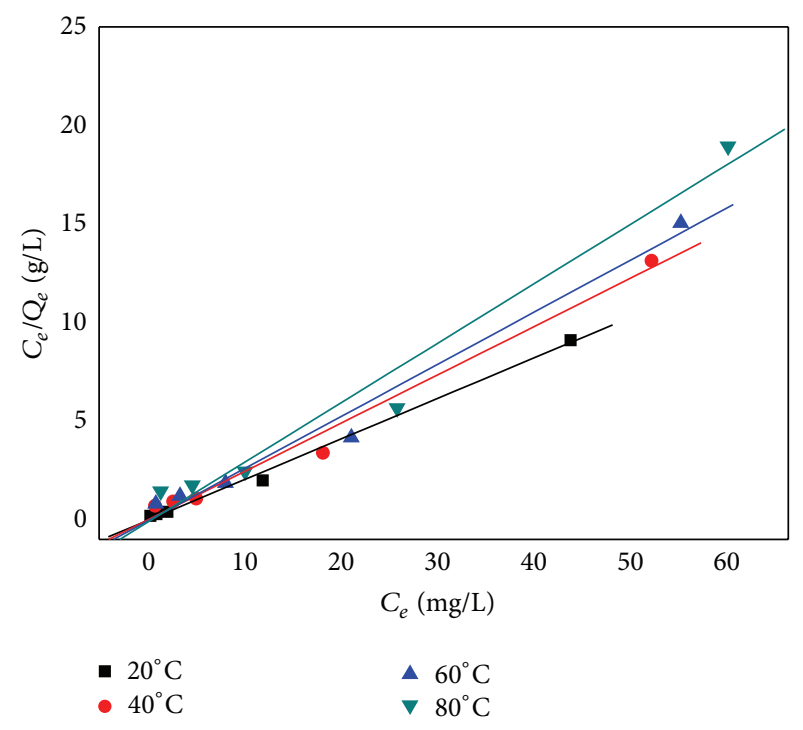

(a)

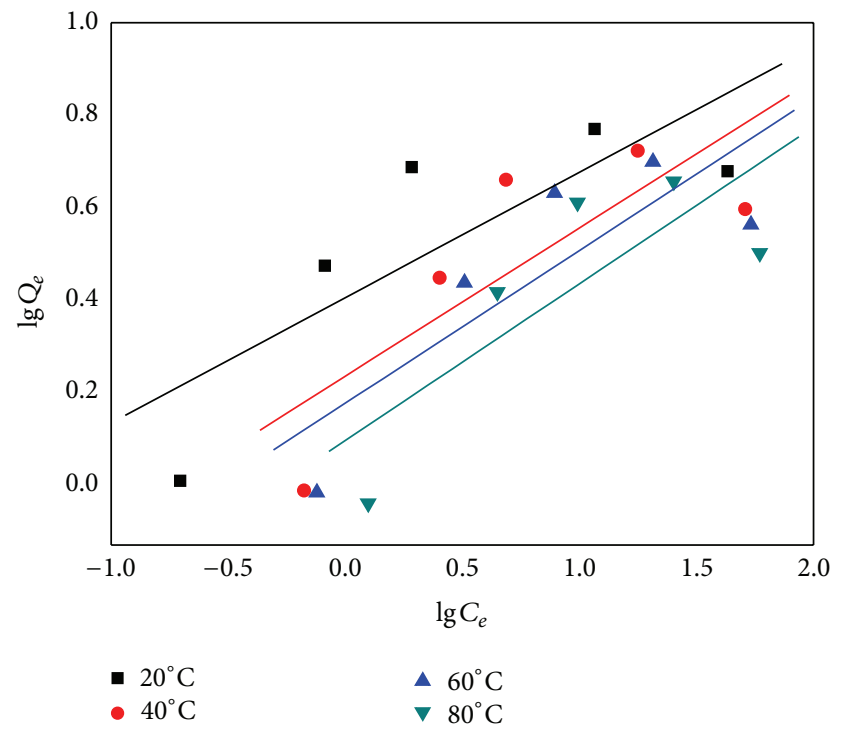

(b)

FIGURE 5: Linearized form plots of Langmuir (a) and Freundlich (b) isotherms for phosphate adsorption by dolomite.

temperature decreasing indicated that the adsorption is easier at low than at high temperature.

Other thermodynamic parameters such as enthalpy change $\left(\Delta H^{\theta}\right)$ and entropy change $\left(\Delta S^{\theta}\right)$ are evaluated using van't Hoff equation. The negative values of $\Delta G^{\theta}$ indicate the spontaneous and highly favorable nature of adsorption:

$$
\log k=\frac{\Delta S^{\theta}}{(2.303 R)}-\frac{\Delta H^{\theta}}{(2.303 R T)}
$$

Values of $\Delta H^{\theta}$ and $\Delta S^{\theta}$ were calculated from the slope and intercept of van't Hoff linear plot of $\log k$ versus $1 / T$ (Figure 6) and were listed in Table 5. The negative value of $\Delta H^{\theta}$ confirms the exothermic nature of phosphate 


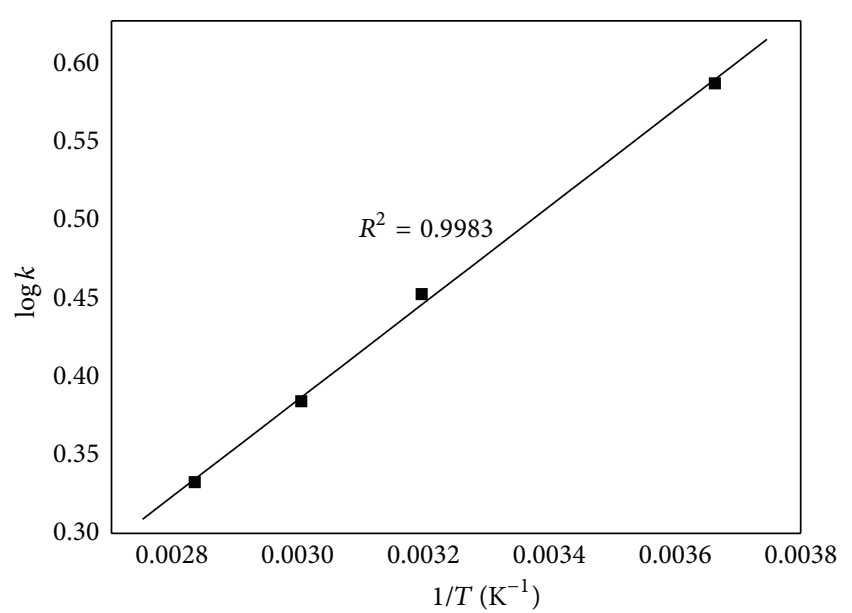

Figure 6: Plot of $\log k$ versus $1 / T$ for phosphate adsorption by dolomite.

adsorption onto dolomite. The negative value of $\Delta S^{\theta}$ suggests that the randomness at the solid/solution interface decreases during the phosphate adsorption, and it governs the possibility of chemical adsorption. Entropy of activation can be regarded as a measure of the "saddle point energy" over which reactant molecule must pass as activated complex; $\Delta S^{\theta}$ conveys whether a particular reaction proceeds faster or slower than another individual reaction [28].

It is well known that phosphate adsorption reaction belongs to endothermic reaction for most adsorbents, for example, $\mathrm{Fe}(\mathrm{III}) / \mathrm{Cr}$ (III) hydroxide, red mud, and iron oxide tailings [29-31]. Considering the fact that the reaction of phosphate adsorption onto dolomite is exothermic, a relatively high phosphate removal rate is expected to be obtained at room temperature, and the energy consumed to heat up can be saved, which favors the industrial application of dolomite in phosphate removal.

\section{Conclusions}

(1) Dolomite removes phosphate from aqueous solution rapidly. Phosphate may be removed by adsorption and/or by precipitation of calcium phosphate.

(2) The adsorption kinetics characteristics of phosphate on dolomite were well described by pseudo-secondorder model. The mechanism of the phosphate removal process is mainly controlled by chemical bonding or chemisorption.

(3) Equilibrium isotherm adsorption data obey Langmuir isotherms. The maximum adsorption capacity of dolomite is $4.76 \mathrm{mg} / \mathrm{g} \mathrm{P}$.

(4) Thermodynamic studies indicated that the phosphate adsorption on dolomite was exothermic.

(5) Dolomite can be used as an effective and low-cost adsorbent for the removal of phosphate.

\section{Conflict of Interests}

The authors declare that there is no conflict of interests regarding the publication of this paper.

\section{Acknowledgments}

This research was funded by Research Foundation of Chongqing University of Science \& Technology, Project no. CK2014Z23. This work was also financially supported by the National Natural Science Foundation of China (Grant no. 51174246 and Grant no. 51204221) and the Scientific and Technological Research Program of Chongqing Municipal Education Commission (no. KJ131417).

\section{References}

[1] J. B. Xiong, Y. Qin, E. Islam, M. Yue, and W. F. Wang, "Phosphate removal from solution using powdered freshwater mussel shells," Desalination, vol. 276, no. 2-3, pp. 317-321, 2011.

[2] L. F. Greenlee, F. Testa, D. F. Lawler, B. D. Freeman, and P. Moulin, "The effect of antiscalant addition on calcium carbonate precipitation for a simplified synthetic brackish water reverse osmosis concentrate," Water Research, vol. 44, no. 9, pp. 2957-2969, 2010.

[3] F. Wang, S. Lu, Y. Wei, and M. Ji, "Characteristics of aerobic granule and nitrogen and phosphorus removal in a SBR," Journal of Hazardous Materials, vol. 164, no. 2-3, pp. 1223-1227, 2009.

[4] Y.-T. Liu and D. Hesterberg, "Phosphate bonding on noncrystalline Al/Fe-hydroxide coprecipitates," Environmental Science \& Technology, vol. 45, no. 15, pp. 6283-6289, 2011.

[5] L. Johansson, "Industrial by-products and natural substrata as phosphorus sorbents," Environmental Technology, vol. 20, no. 3, pp. 309-316, 1999.

[6] H. Zeng, B. Fisher, and D. E. Giammar, "Individual and competitive adsorption of arsenate and phosphate to a highsurface-area iron oxide-based sorbent," Environmental Science and Technology, vol. 42, no. 1, pp. 147-152, 2008.

[7] E. W. Shin, J. S. Han, M. Jang, S.-H. Min, J. K. Park, and R. M. Rowell, "Phosphate adsorption on aluminum-impregnated mesoporous silicates: surface structure and behavior of adsorbents," Environmental Science and Technology, vol. 38, no. 3, pp. 912-917, 2004.

[8] K. Sakadevan and H. J. Bavor, "Phosphate adsorption characteristics of soils, slags and zeolite to be used as substrates in constructed wetland systems," Water Research, vol. 32, no. 2, pp. 393-399, 1998.

[9] L. Zeng, X. M. Li, and J. D. Liu, "Adsorptive removal of phosphate from aqueous solutions using iron oxide tailings," Water Research, vol. 38, no. 5, pp. 1318-1326, 2004.

[10] X. Song, Y. Pan, Q. Wu, Z. Cheng, and W. Ma, "Phosphate removal from aqueous solutions by adsorption using ferric sludge," Desalination, vol. 280, no. 1-3, pp. 384-390, 2011.

[11] B. Kostura, H. Kulveitová, and J. Leško, "Blast furnace slags as sorbents of phosphate from water solutions," Water Research, vol. 39, no. 9, pp. 1795-1802, 2005.

[12] C. A. Prochaska and A. I. Zouboulis, "Removal of phosphates by pilot vertical-flow constructed wetlands using a mixture of sand and dolomite as substrate," Ecological Engineering, vol. 26, no. 3, pp. 293-303, 2006. 
[13] X. L. Yuan, W. T. Xia, J. An, W. Q. Yang, and J. G. Yin, "Removal of phosphate anions from aqueous solutions using dolomite as adsorbent," Advanced Materials Research, vol. 864-867, pp. 1454-1457, 2014.

[14] Y.-S. Ho, "Citation review of Lagergren kinetic rate equation on adsorption reactions," Scientometrics, vol. 59, no. 1, pp. 171-177, 2004.

[15] Y. S. Ho and G. McKay, "Pseudo-second order model for sorption processes," Process Biochemistry, vol. 34, no. 5, pp. 451$465,1999$.

[16] M. A. Hanif, R. Nadeem, M. N. Zafar, K. Akhtar, and H. N. Bhatti, "Kinetic studies for $\mathrm{Ni}(\mathrm{II})$ biosorption from industrial wastewater by Cassia fistula (Golden Shower) biomass," Journal of Hazardous Materials, vol. 145, no. 3, pp. 501-505, 2007.

[17] I. A. Şengil and M. Özacar, "Treatment of dairy wastewaters by electrocoagulation using mild steel electrodes," Journal of Hazardous Materials, vol. 137, no. 2, pp. 1197-1205, 2006.

[18] J.-P. Boisvert, T. C. To, A. Berrak, and C. Jolicoeur, "Phosphate adsorption in flocculation processes of aluminium sulphate and poly-aluminium-silicate-sulphate," Water Research, vol. 31, no. 8, pp. 1939-1946, 1997.

[19] D. Y. Wu, B. H. Zhang, C. J. Li, Z. J. Zhang, and H. N. Kong, "Simultaneous removal of ammonium and phosphate by zeolite synthesized from fly ash as influenced by salt treatment," Journal of Colloid and Interface Science, vol. 304, no. 2, pp. 300-306, 2006.

[20] S. Karaca, A. Gürses, M. Ejder, and M. Açikyildiz, "Adsorptive removal of phosphate from aqueous solutions using raw and calcinated dolomite," Journal of Hazardous Materials, vol. 128, no. 2-3, pp. 273-279, 2006.

[21] J. Yan, D. W. Kirk, C. Q. Jia, and X. Liu, "Sorption of aqueous phosphorus onto bituminous and lignitous coal ashes," Journal of Hazardous Materials, vol. 148, no. 1-2, pp. 395-401, 2007.

[22] N. M. Agyei, C. A. Strydom, and J. H. Potgieter, "The removal of phosphate ions from aqueous solution by fly ash, slag, ordinary Portland cement and related blends," Cement and Concrete Research, vol. 32, no. 12, pp. 1889-1897, 2002.

[23] R. X. Liu, J. L. Guo, and H. X. Tang, "Adsorption of fluoride, phosphate, and arsenate ions on a new type of ion exchange fiber," Journal of Colloid and Interface Science, vol. 248, no. 2, pp. 268-274, 2002.

[24] P. B. Bhakat, A. K. Gupta, S. Ayoob, and S. Kundu, "Investigations on arsenic(V) removal by modified calcined bauxite," Colloids and Surfaces A: Physicochemical and Engineering Aspects, vol. 281, no. 1-3, pp. 237-245, 2006.

[25] A. Dimirkou, A. Ioannou, and M. Doula, "Preparation, characterization and sorption properties for phosphates of hematite, bentonite and bentonite-hematite systems," Advances in Colloid and Interface Science, vol. 97, no. 1-3, pp. 37-61, 2002.

[26] L. Johansson and J. P. Gustafsson, "Phosphate removal using blast furnace slags and opoka-mechanisms," Water Research, vol. 34, no. 1, pp. 259-265, 2000.

[27] Q. L. Fu, Y. L. Deng, H. S. Li et al., "Equilibrium, kinetic and thermodynamic studies on the adsorption of the toxins of Bacillus thuringiensis subsp. kurstaki by clay minerals," Applied Surface Science, vol. 255, no. 8, pp. 4551-4557, 2009.

[28] S. D. Pardeshi, J. P. Sonar, A. M. Zine, and S. N. Thore, "Kinetic and thermodynamic study of adsorption of methylene blue and rhodamine B on adsorbent prepared from Hyptis suaveolens (Vilayti Tulsi)," Journal of the Iranian Chemical Society, vol. 10, no. 6, pp. 1159-1166, 2013.
[29] C. Namasivayam and K. Prathap, "Recycling Fe(III)/Cr(III) hydroxide, an industrial solid waste for the removal of phosphate from water," Journal of Hazardous Materials, vol. 123, no. 1-3, pp. 127-134, 2005.

[30] W. Huang, S. Wang, Z. Zhu et al., "Phosphate removal from wastewater using red mud," Journal of Hazardous Materials, vol. 158, no. 1, pp. 35-42, 2008.

[31] L. Zeng, X. Li, and J. Liu, "Adsorptive removal of phosphate from aqueous solutions using iron oxide tailings," Water Research, vol. 38, no. 5, pp. 1318-1326, 2004. 

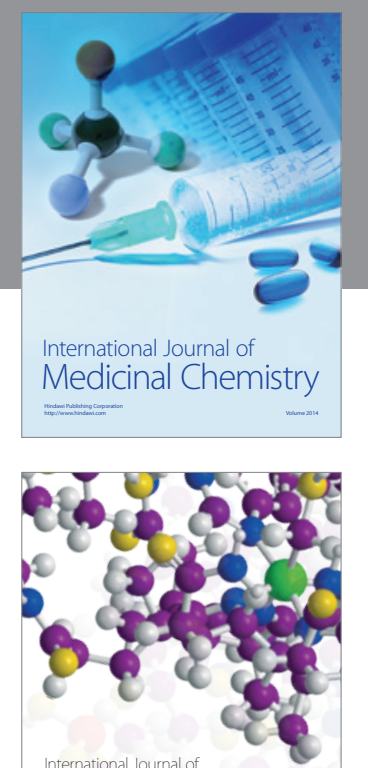

\section{Carbohydrate} Chemistry

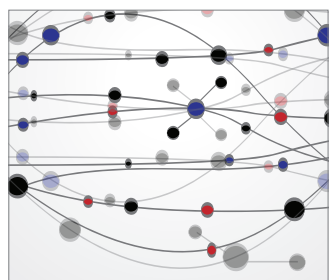

The Scientific World Journal
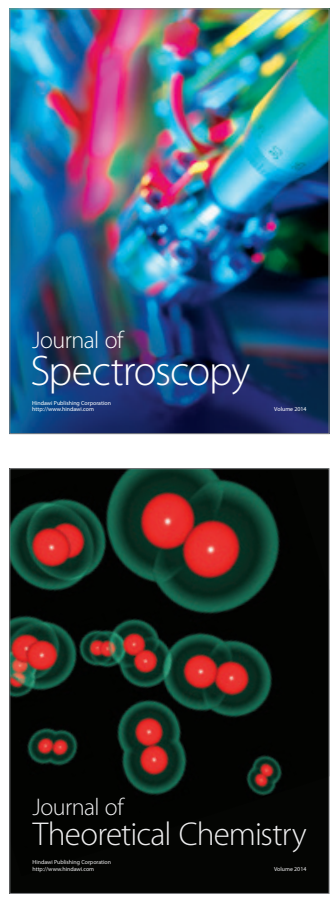
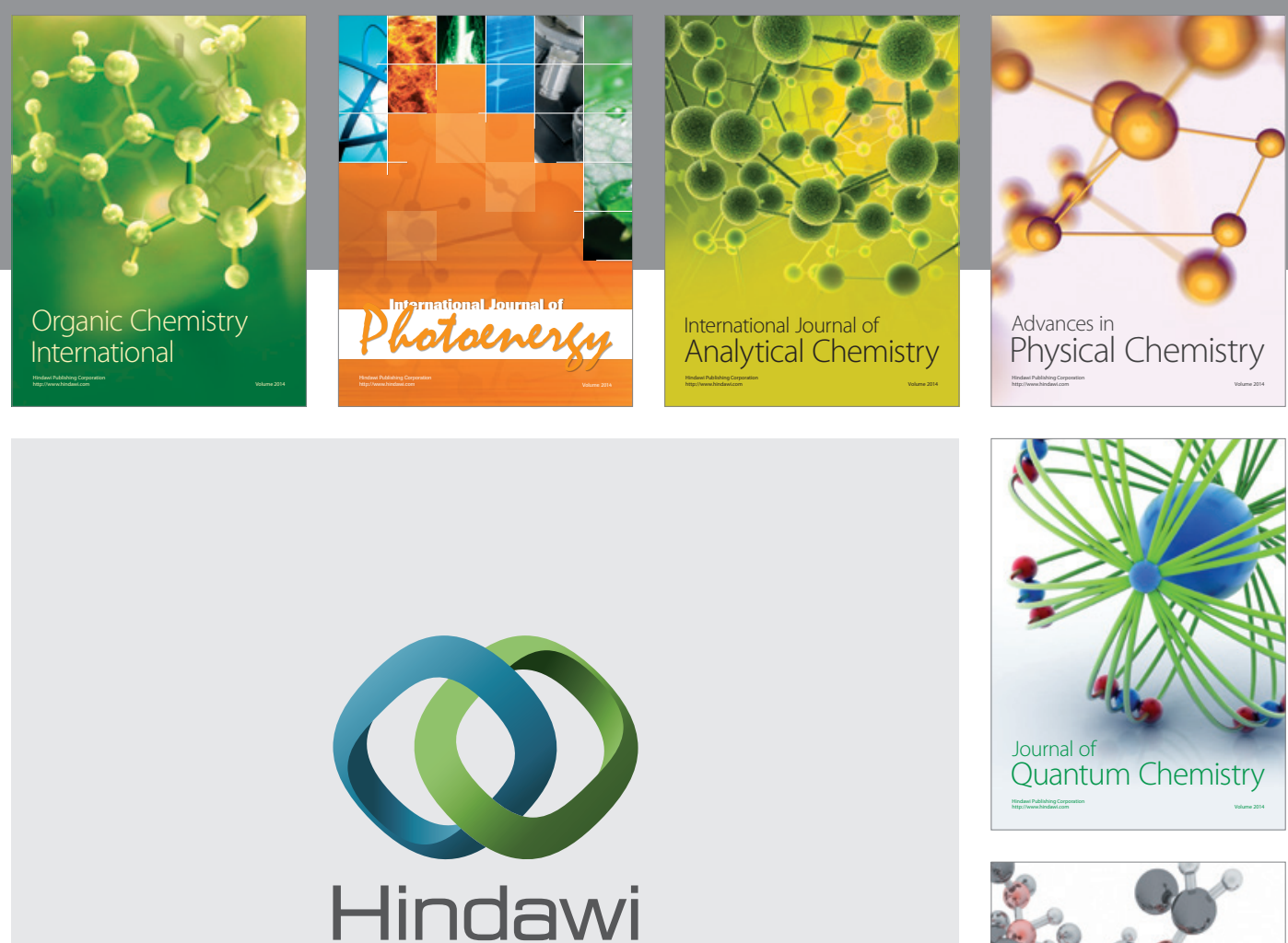

Submit your manuscripts at

http://www.hindawi.com

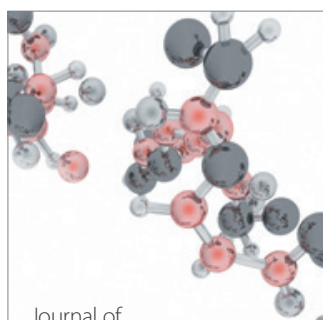

Analytical Methods

in Chemistry

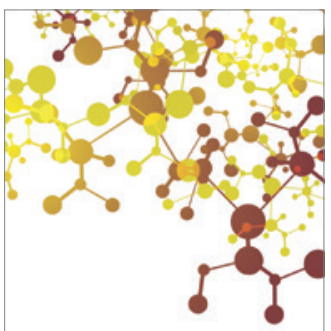

Journal of

Applied Chemistry

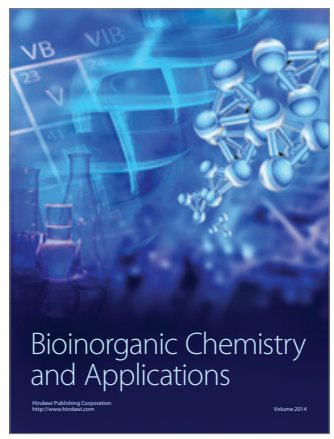

Inorganic Chemistry
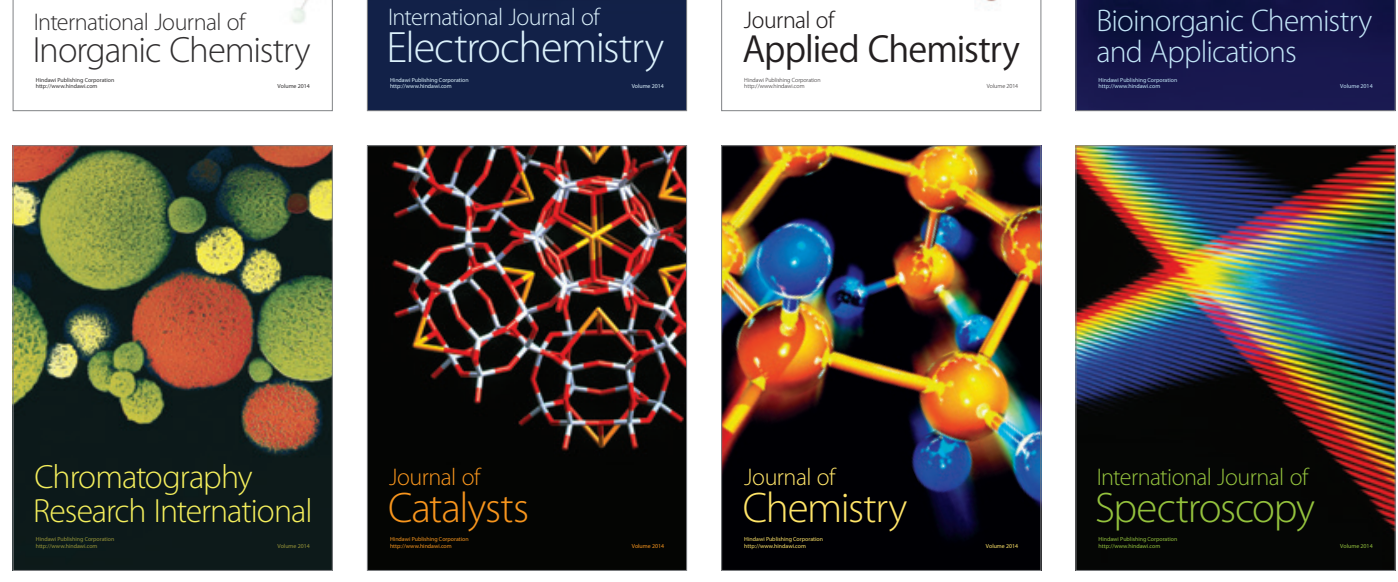